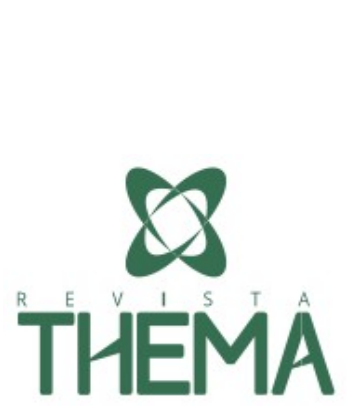

CIÊNCIAS HUMANAS

\section{A multiplicação nos anos iniciais do Ensino Fundamental: da teoria para a prática}

The multiplication in the early years of Elementary School:

from theory to practice

Malcus Cassiano Kuhn' ${ }^{1}$, Jesiane de Freitas Pereira ${ }^{2}$

\title{
RESUMO
}

O artigo contempla o ensino da multiplicação nos anos iniciais do Ensino Fundamental, com uma abordagem qualitativa, através de um estudo bibliográfico, embasado na Teoria de Aprendizagem Significativa, no Campo Conceitual Multiplicativo de Vergnaud e na BNCC. Traz reflexões sobre o contexto da Matemática que explora o princípio multiplicativo nos anos iniciais e sugere práticas pedagógicas para qualificar o trabalho em sala de aula. A área de Matemática na BNCC apresenta a multiplicação na unidade temática números, a partir do 2o ano, e é desenvolvida de forma gradativa, explorando-se as ideias de adição de parcelas iguais, proporcionalidade, disposição retangular e combinação. Acredita-se que a resolução e elaboração de problemas, atividades investigativas, o uso de materiais concretos, jogos e recursos tecnológicos, sejam fundamentais no processo de ensino da multiplicação, para promoção de uma aprendizagem significativa. O professor deve planejar situações de aprendizagem que envolvam os estudantes de forma ativa na construção dos conceitos de multiplicação, considerando as orientações da BNCC e a realidade escolar.

Palavras-chave: Multiplicação; campo conceitual; BNCC; ensino; aprendizagem significativa.

\section{ABSTRACT}

The article contemplates the teaching of the multiplication in the early years of Elementary School, with a qualitative approach, through a bibliographic study, based on the Theory of Meaningful Learning, Vergnaud's Multiplicative Conceptual Field and BNCC. It brings reflections on the context of Mathematics that explores the multiplicative principle in the early years and suggests pedagogical practices to qualify work in the classroom. The Mathematics area at BNCC presents the multiplication in the thematic unit numbers, from the 2nd year onwards, and is developed gradually, exploring the ideas of adding equal portions, proportionality, rectangular arrangement and combination. It is believed that problem solving and elaboration, investigative activities, the use of concrete materials, games and technological resources, are fundamental in the process of teaching multiplication, in order to promote meaningful learning. The teacher should plan learning situations that actively involve students in the construction of multiplication concepts, considering the guidelines of the BNCC and the school reality.

Keywords: Multiplication; conceptual field; BNCC; teaching; meaningful learning.

\footnotetext{
${ }^{1}$ Instituto Federal de Educação, Ciência e Tecnologia Sul-rio-grandense - IFSul, Câmpus Lajeado/RS Brasil. E-mail: malcuskuhn@ifsul.edu.br

${ }^{2}$ Idem. E-mail: jesianefpereira@gmail.com
} 


\section{INTRODUÇÃO}

Este artigo é um trabalho de conclusão de curso de uma Especialização na área de Educação, voltada para os anos iniciais do Ensino Fundamental (EF), de uma Instituição Federal do Rio Grande do Sul. Apresenta reflexões sobre o ensino da multiplicação nos anos iniciais do EF.

Trabalhar Matemática nos anos iniciais, sempre foi um desafio para os professores, devido às dificuldades apresentadas por pelos estudantes. Segundo dados do Sistema de Avaliação da Educação Básica (Saeb), somente 15,52\% dos estudantes saem do 5응 ano do EF com conhecimento adequado em Matemática e 51,35\% com conhecimento básico. Já no último ano do EF, esses índices passam para 32,39\%, com conhecimento básico, e apenas 4,5\%, adequado (BRASIL, 2017a). Diante desse contexto, investigamse teorias educacionais e documentos legais para tecer reflexões sobre o contexto da Matemática que explora o princípio multiplicativo desenvolvido nos anos iniciais do EF, bem como, sugerir práticas pedagógicas que possam qualificar o trabalho em sala de aula.

Dessa forma, a abordagem da pesquisa é qualitativa, pois de acordo com Prodanov e Freitas (2013, p.70):

Os dados coletados nessas pesquisas são descritivos, retratando o maior número possível de elementos existentes na realidade estudada. Preocupa-se muito mais com o processo do que com o produto. $\mathrm{Na}$ análise dos dados coletados, não há preocupação em comprovar hipóteses previamente estabelecidas, porém estas não eliminam a existência de um quadro teórico que direcione a coleta, a análise e a interpretação dos dados.

Nesse sentido, o procedimento técnico empregado é o estudo bibliográfico que se utiliza de material já publicado, constituído basicamente de livros e artigos (GIL, 2017). Está embasado na Teoria de Aprendizagem Significativa (TAS), no Campo Conceitual Multiplicativo de Vergnaud e na Base Nacional Comum Curricular (BNCC).

O presente texto está organizado em sete seções. Terminada esta parte de introdução do artigo, registram-se os aportes teóricos nas três seções seguintes, para na quinta seção discutir a multiplicação em sala de aula. Finalizando, apresentam-se as considerações finais sobre o estudo realizado, seguido das referências utilizadas.

\section{A TEORIA DE APRENDIZAGEM SIGNIFICATIVA}

A Teoria da Aprendizagem Significativa ou Teoria da Assimilação de Ausubel (1968, 1978, 1980 apud MOREIRA, 2012) é uma teoria que propõe explicar o processo de aprendizagem que ocorre na mente humana, através da organização e integração do material de aprendizagem na estrutura cognitiva. Conforme Moreira (2012), a TAS considera necessárias duas condições para que a aprendizagem ocorra de forma significativa: a disposição do estudante para aprender e o material didático desenvolvido deve ser potencialmente significativo para o estudante, além de ser construído a partir dos seus conhecimentos prévios. Nesse sentido, o autor afirma que: 
A aprendizagem significativa é aquela em que as ideias expressas simbolicamente interagem de maneira substantiva e não-arbitrária com aquilo que o aprendiz já sabe. Substantiva quer dizer não-literal, não ao pé da letra, e não-arbitrária significa que a interação não é com qualquer ideia prévia, mas sim com algum conhecimento especificamente relevante já existente na estrutura cognitiva do sujeito que aprende. (MOREIRA, 2012, p.13).

Por isso, é importante que o planejamento do professor, considerando a proposta curricular da escola, seja organizado em situações de aprendizagens que possibilitem a construção de outras, em uma sequência lógica de objetos de conhecimento necessários para o desenvolvimento de habilidades. Ainda, segundo Moreira (2012. p.10), as subsunções, conhecimentos prévios especificadamente relevantes, como facilitadores para a aprendizagem de outros, estão definidas em "preposições, modelos mentais, concepções, ideias, representações ou conceitos que estão disponíveis na estrutura cognitiva de quem aprende." São os conhecimentos prévios determinados por experiências anteriores desse sujeito.

Considera-se importante que o estudante seja estimulado pelo professor na construção de novas habilidades. Novak e Cañas, seguidores de Ausubel, propõem três condições essenciais para a ocorrência da aprendizagem significativa:

I) Material a ser aprendido deve ser conceitualmente claro e apresentado com linguagem e exemplos relacionáveis com o conhecimento anterior do aprendiz. [...] II) $\mathrm{O}$ aprendiz deve possuir conhecimento anterior relevante. [...] III) O aprendiz precisa ter vontade de aprender de modo significativo. A única condição sobre a qual o professor ou mentor não possui controle direto é a da motivação dos estudantes em aprender tentando incorporar novos significados ao seu conhecimento prévio, em vez de simplesmente memorizando definições de conceitos ou afirmações proposicionais, ou ainda procedimentos computacionais. (NOVAK; CAÑAS, 2010, p.11).

Esses autores abordam a importância do planejamento da aula se relacionar com experiências anteriores, vivenciadas pelo estudante, possibilitando o uso dessas na construção de novas aprendizagens motivadas e mediadas pelo professor, dando significado ao que está sendo proposto. Para tanto, sugere-se o uso de materiais concretos, jogos e tecnologias, de modo a favorecer o estudante na construção de novos conhecimentos.

Moreira (2012) compara a aprendizagem significativa com a aprendizagem mecânica. Ainda hoje, existem professores que, em suas práticas pedagógicas, empregam a memorização de conteúdos pelo estudante, que a utiliza em avaliações diagnósticas de aprendizagem, resumindo-se em uma transcrição fiel, feita pelo estudante, de algo sem compreensão e conexão lógica. Para o autor, as duas aprendizagens não se dividem no decorrer da construção do conhecimento pelo estudante, mas sim, passam em uma zona cinza que, com conceitos adequados a serem desenvolvidos pelo professor, possibilita a ponte da aprendizagem mecânica para a significativa, como mostra a Figura 1: 
Figura 1 - Transição da aprendizagem mecânica para a aprendizagem significativa.

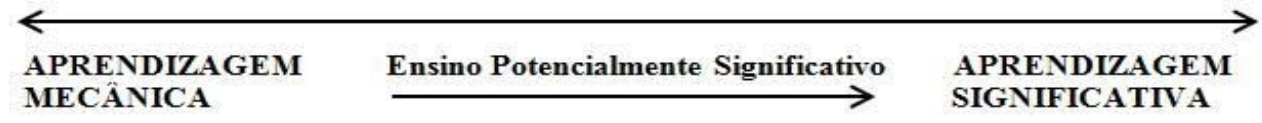

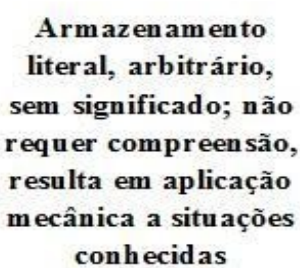

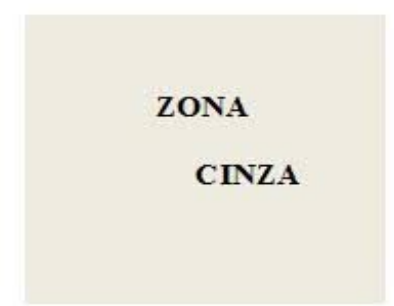

Fonte: (MOREIRA, 2012, p.32).
Incorporação substantiva, não arbitrária, com significado; implica compreen são, tran sferência, cap acidade de explicar, descrever, enfrentar situações novas.

De acordo com Moreira (2012), grande parte do processo de aprendizagem ocorre na zona cinza, um espaço de ensino potencialmente significativo e necessário para progressiva aprendizagem significativa. Porém, para obter sucesso nesse processo de transição, o estudante precisa esforçar-se para fazer as devidas conexões lógicas. Moreira (2012) defende que o professor deve mediar a aprendizagem do estudante para que este consiga relacionar o novo com o preexistente, construindo habilidades condizentes com o conteúdo, devendo utilizar estratégias de ensino e materiais potencialmente significativos, de acordo com o que se espera, de modo a facilitar o entendimento do estudante, tornando o aprendizado significativo.

Como a aprendizagem acontece em diversos contextos, de modos e em tempos diferentes, a mediação do professor é fundamental para oportunizar ao estudante a construção de sua aprendizagem significativa. Moreira associa a aprendizagem significativa a três maneiras diferentes de ensino:

I) A aprendizagem significativa é dita subordinada quando os novos conhecimentos potencialmente significativos adquirem significados, para o sujeito que aprende, por um processo de ancoragem cognitiva, interativa, em conhecimentos prévios relevantes mais gerais e inclusivos já existentes na sua estrutura cognitiva. II) A aprendizagem superordenada envolve, então, processos de abstração, indução, síntese, que levam a novos conhecimentos que passam a subordinar aqueles que Ihes deram origem. III) Aprendizagem combinatória é, então, uma forma de aprendizagem significativa em que a atribuição de significados a um novo conhecimento implica interação com vários outros conhecimentos já existentes na estrutura cognitiva, mas não é nem mais inclusiva nem mais específica do que os conhecimentos originais. (MOREIRA, 2012, p.36-37).

Moreira (2012) relaciona essas três maneiras de aprendizagem significativa a três categorias: representacional (de representações), conceitual (de conceitos) e proposicional (de proposições). A construção dessas categorias pelo estudante requer o acompanhamento do professor, pois é importante que o estudante consiga representar, de forma lógica, o que se pretende com o ensino de determinado objeto de conhecimento para organizar as estruturas mentais embasadas em conhecimentos preexistentes. 


\section{A TEORIA DE APRENDIZAGEM SIGNIFICATIVA}

Pensando em organizar a construção do conhecimento matemático pelo estudante, Vergnaud (2009) propõe situações aditivas para constituição das ideias de adição e subtração, e situações multiplicativas para organização das ideias de multiplicação e divisão. Neste artigo se dará ênfase às situações multiplicativas e às ideias de multiplicação decorrentes destas, englobadas pelo campo conceitual multiplicativo de Vergnaud.

Nos anos iniciais do EF, geralmente, os professores fazem relações entre as operações matemáticas, como a associação da multiplicação com a soma de parcelas iguais, mas deixam de explorar outras ideias para o desenvolvimento do campo conceitual multiplicativo. (VERGNAUD, 2009). Diferentes motivos podem ser encontrados para essas associações entre as operações, destacando-se que:

Pode estar relacionado com a própria concepção de currículo que norteia a ação pedagógica do professor, qual seja: a ideia de que o currículo apresenta uma sequência lógica de conteúdo: primeiro se aprende a adição, depois a subtração e, em seguida, a multiplicação e a divisão. (SANTOS, 2015, p.100).

Para evitar essa sequência lógica de conteúdos, seria importante que o professor criasse diferentes situações de aprendizagem, que oportunizem aos estudantes o contato com as ideias das quatro operações, desde o início da escolarização fundamental. Assim, para promover uma aprendizagem significativa é necessário que o professor contextualize o ensino da multiplicação com o cotidiano dos estudantes, use diferentes estratégias de ensino, como a resolução de problemas e atividades investigativas, além de recursos didáticos diversificados, como: material concreto, jogos pedagógicos e tecnologias.

Os processos de ensino e de aprendizagem da multiplicação deveriam ser estruturados com situações-problema, de acordo com o currículo da escola e da realidade na qual os estudantes estão inseridos. O estudante precisa ser capaz de esquematizar e representar a resolução de atividades mais simples, envolvendo a multiplicação, possibilitando o entendimento das mais complexas.

O professor deveria estar preparado para frustrações em seus métodos de ensino e construir algo focado na gênese do erro (PINTO, 2000), ou seja, é preciso considerar todo o processo de resolução empregado pelo estudante e não apenas o resultado final. Nesse sentido, a teoria dos campos conceituais ajuda o professor a diagnosticar dificuldades apresentadas pelo estudante na resolução de situações sujeitadas a ele. Vergnaud (1982, p.40) defende "como premissa que o conhecimento está organizado em campos conceituais cujo domínio, por parte dos sujeitos, ocorre ao longo de um largo período de tempo, através de experiência, maturidade e aprendizagem". 0 mesmo autor define o campo conceitual como "um conjunto informal e heterogêneo de problemas, situações, conceitos, relações, estruturas, conteúdos e operações de pensamento, conectados uns aos outros e, provavelmente, entrelaçados durante o processo de aquisição." (VERGNAUD, 1982, p.40).

Geralmente, o professor espera que os estudantes, na resolução de situações multiplicativas, façam a relação com conhecimentos previamente adquiridos no 
estudo de situações aditivas. Mas, ele não pode considerar que todos irão conseguir estabelecer essas relações, pois os estudantes podem ter ficado com lacunas na aprendizagem e capazes de prejudicar a construção de novos conhecimentos. Por isso, é importante que o professor conheça e compreenda o campo conceitual aditivo e o multiplicativo. Destaca-se que o campo conceitual multiplicativo, é definido por Vergnaud, como:

O Campo Conceitual Multiplicativo ou Estruturas Multiplicativas é o conjunto das situações que podem ser resolvidas com o uso de uma ou de várias multiplicações ou divisões e os conceitos e teoremas que permitem analisar e resolvê-las, como, por exemplo: proporção simples, proporção múltipla, fração, múltiplo, divisor, entre outros. (VERGNAUD, 1996, p.168).

A partir dessa definição de campo conceitual multiplicativo, expressa por Vergnaud, apresentam-se situações multiplicativas no Quadro 1:

Quadro 1 - Situações multiplicativas a partir do campo conceitual multiplicativo.

Multiplicação aditiva (ideia de adição de parcelas iguais): situações que associam a multiplicação como uma adição de parcelas iguais.

Exemplo: Caio foi ao supermercado e comprou 3 pacotes de pirulitos. Cada pacote tem 12 pirulitos. Quantos pirulitos Caio comprou?

Comparação entre razões (ideia de proporcionalidade): situações que envolvem a correspondência "um para muitos", "dois para o dobro de muitos" e assim por diante, ou seja, a base do conceito de proporção.

Exemplo: Para fazer refresco de uva, utilizam-se 4 copos de água para cada copo de suco concentrado. Quantos copos de água são necessários para fazer refresco usando 2 copos de suco concentrado? E usando 3 copos? E 4 copos?

Configuração retangular (ideia de disposição retangular): situações que exploram a leitura de linha por coluna ou vice-versa.

Exemplo: Uma sala de aula tem 6 fileiras com 5 cadeiras cada uma. Quantas cadeiras há nessa sala?

Raciocínio combinatório (ideia de combinação): situações que envolvem a necessidade de verificar as possibilidades de combinar elementos de diferentes conjuntos.

Exemplo: Uma lanchonete oferece 3 tipos de pastel (carne, queijo e palmito) e 4 tipos de suco (laranja, uva, morango e acerola). Quantas são as possibilidades de escolha de um pastel e um suco?

Fonte: Adaptado de Vergnaud (2009).

Portanto, essas situações estão relacionadas aos quatro significados da multiplicação: adição de parcelas iguais, proporcionalidade, configuração retangular e combinação; referenciados no documento da BNCC, para os anos iniciais do EF, conforme discutido na próxima seção deste artigo.

\section{A MULTIPLICAÇÃO NA BNCC}

Em 2017, foi promulgada a versão final da BNCC para a Educação Infantil (EI) e o EF no país. Para o EF, a BNCC propõe uma progressão múltipla de aprendizagens, articulando o trabalho do professor com as experiências já vivenciadas pelos estudantes, valorizando as situações lúdicas de aprendizagem para estimular o 
pensamento lógico e criativo, proporcionando o desenvolvimento das capacidades de perguntar, argumentar, interagir e ampliar a compreensão do mundo. No documento da BNCC se encontra que:

Ao longo do Ensino Fundamental - Anos Iniciais, a progressão do conhecimento ocorre pela consolidação das aprendizagens anteriores e pela ampliação das práticas de linguagem e da experiência estética e intercultural das crianças, considerando tanto seus interesses e suas expectativas quanto o que ainda precisam aprender. (BRASIL, 2017b, p.59).

As cinco unidades temáticas apresentadas pela BNCC para o ensino de Matemática, do $1^{\circ}$ ao $5^{\circ}$ ano, pensadas de modo a complementar uma à outra, são: números, álgebra, geometria, grandezas e medidas, probabilidade e estatística. (BRASIL, 2017b). Essas temáticas estão interligadas como um quebra-cabeça, ou seja, uma essencial à outra, precisando o professor estar em sintonia com os estudantes, pois todos os anos ele irá rever conhecimentos já estudados para ajudar na compreensão de outros, o que vai ao encontro da TAS.

Dentro de cada unidade temática, a BNCC apresenta objetos de conhecimento (conteúdos) e habilidades (objetivos de aprendizagem) para serem desenvolvidos com os estudantes ao longo dos anos. A operação de multiplicação se encontra na unidade temática "números", a partir do 20 ano do EF, e é desenvolvida de forma gradativa, explorando-se as ideias de adição de parcelas iguais, proporcionalidade, disposição retangular e combinação. "A unidade temática números tem como finalidade desenvolver o pensamento numérico, implica no conhecimento de maneiras à quantificar atributos de objetos e de julgar e interpretar argumentos baseados em quantidades." (BRASIL, 2017b, p.266). No Quadro 2, apresentam-se os objetos de conhecimento e habilidades relacionados à multiplicação, do $2^{\circ}$ a ao 5으 ano do $E F$, de acordo com a BNCC:

Quadro 2 - A operação de multiplicação na BNCC.

\begin{tabular}{|l|l|l|}
\hline Ano & $\begin{array}{l}\text { Objetos de } \\
\text { conhecimento }\end{array}$ & Habilidades \\
\hline \multirow{2}{*}{$\underline{0}$} & $\begin{array}{l}\text { Problemas envolvendo } \\
\text { adição de parcelas iguais } \\
\text { (multiplicação). }\end{array}$ & $\begin{array}{l}\text { (EF02MA07) } \\
\text { multiplicação (por 2, 3, 4 e 5) com a ideia de adição de } \\
\text { parcelas iguais por meio de estratégias e formas de } \\
\text { registro pessoais, utilizando ou não suporte de imagens } \\
\text { e/ou material manipulável. }\end{array}$ \\
\cline { 2 - 3 } & $\begin{array}{l}\text { Problemas envolvendo } \\
\text { significados de dobro, } \\
\text { metade, triplo e terça parte. }\end{array}$ & $\begin{array}{l}\text { (EF02MA08) Resolver e elaborar problemas envolvendo } \\
\text { dobro, metade, triplo e terça parte, com o suporte de } \\
\text { imagens ou material manipulável, utilizando } \\
\text { estratégias pessoais. }\end{array}$ \\
\hline
\end{tabular}

${ }^{3}$ Cada habilidade é identificada com um código alfanumérico, cuja composição é a seguinte: o primeiro par de letras indica a etapa Ensino Fundamental, o primeiro par de números indica o ano (2o ano), o segundo par de letras indica o componente curricular Matemática e o último par de números indica a posição da habilidade na numeração sequencial do ano (habilidade 07). 


\begin{tabular}{|c|c|c|}
\hline \multirow[b]{2}{*}{30} & $\begin{array}{l}\text { Construção de fatos } \\
\text { fundamentais da }[\ldots] \\
\text { multiplicação. }\end{array}$ & $\begin{array}{l}\text { (EF03MA03) Construir e utilizar fatos básicos }[. . .] \text { da } \\
\text { multiplicação para o cálculo mental ou escrito. }\end{array}$ \\
\hline & $\begin{array}{l}\text { Problemas envolvendo } \\
\text { diferentes significados da } \\
\text { multiplicação [...]: adição de } \\
\text { parcelas iguais, } \\
\text { configuração retangular, } \\
\text { [...]. }\end{array}$ & $\begin{array}{l}\text { (EF03MA07) Resolver e elaborar problemas de } \\
\text { multiplicação (por } 2,3,4,5 \text { e 10) com os significados } \\
\text { de adição de parcelas iguais e elementos apresentados } \\
\text { em disposição retangular, utilizando diferentes } \\
\text { estratégias de cálculo e registros. }\end{array}$ \\
\hline \multirow{4}{*}{$4 \stackrel{0}{2}$} & $\begin{array}{l}\text { Composição e } \\
\text { decomposição de um } \\
\text { número natural de até cinco } \\
\text { ordens, por meio de adições } \\
\text { e multiplicações por } \\
\text { potências de } 10 \text {. }\end{array}$ & $\begin{array}{l}\text { (EF04MA02) Mostrar, por decomposição e composição, } \\
\text { que todo número natural pode ser escrito por meio de } \\
\text { adições e multiplicações por potências de dez, para } \\
\text { compreender o sistema de numeração decimal e } \\
\text { desenvolver estratégias de cálculo. }\end{array}$ \\
\hline & $\begin{array}{l}\text { Propriedades das operações } \\
\text { para o desenvolvimento de } \\
\text { diferentes estratégias de } \\
\text { cálculo com números } \\
\text { naturais. }\end{array}$ & $\begin{array}{l}\text { (EF04MA04) Utilizar as relações entre [...] multiplicação } \\
\text { e divisão, para ampliar as estratégias de cálculo. } \\
\text { (EF04MA05) Utilizar as propriedades das operações } \\
\text { para desenvolver estratégias de cálculo. }\end{array}$ \\
\hline & $\begin{array}{l}\text { Problemas envolvendo } \\
\text { diferentes significados da } \\
\text { multiplicação [...]: adição de } \\
\text { parcelas iguais, } \\
\text { configuração retangular, } \\
\text { proporcionalidade, }[\ldots]\end{array}$ & $\begin{array}{l}\text { (EF04MA06) Resolver e elaborar problemas envolvendo } \\
\text { diferentes significados da multiplicação (adição de } \\
\text { parcelas iguais, organização retangular e } \\
\text { proporcionalidade), utilizando estratégias diversas, } \\
\text { como cálculo por estimativas, cálculo mental e } \\
\text { algoritmos. }\end{array}$ \\
\hline & Problemas de contagem. & $\begin{array}{l}\text { (EF04MA08) Resolver, com suporte de imagem e/ou } \\
\text { material manipulável, problemas simples de contagem, } \\
\text { como a determinação do número de agrupamentos } \\
\text { possíveis ao se combinar cada elemento de uma } \\
\text { coleção com todos os elementos de outra, utilizando } \\
\text { estratégias e formas de registro pessoais. }\end{array}$ \\
\hline \multirow[b]{2}{*}{5 은 } & $\begin{array}{l}\text { Problemas: multiplicação } \\
\text { [...] de números racionais } \\
\text { cuja representação decimal } \\
\text { é finita por números } \\
\text { naturais. }\end{array}$ & $\begin{array}{l}\text { (EF05MA08) Resolver e elaborar problemas de } \\
\text { multiplicação [...] com números naturais [...], utilizando } \\
\text { estratégias diversas, como cálculo por estimativa, } \\
\text { cálculo mental e algoritmos. }\end{array}$ \\
\hline & $\begin{array}{l}\text { Problemas de contagem do } \\
\text { tipo: "Se cada objeto de } \\
\text { uma coleção A for } \\
\text { combinado com todos os } \\
\text { elementos de uma coleção } \\
\text { B, quantos agrupamentos } \\
\text { desse tipo podem ser } \\
\text { formados?". }\end{array}$ & $\begin{array}{l}\text { (EF05MA09) Resolver e elaborar problemas simples de } \\
\text { contagem envolvendo o princípio multiplicativo, como } \\
\text { a determinação do número de agrupamentos possíveis } \\
\text { ao se combinar cada elemento de uma coleção com } \\
\text { todos os elementos de outra coleção, por meio de } \\
\text { diagramas de árvore ou por tabelas. }\end{array}$ \\
\hline
\end{tabular}

Fonte: Adaptado de Brasil (2017b).

Ao analisar os objetos de conhecimento e habilidades a serem construídos pelos estudantes, nos anos iniciais do EF, é possível observar que o nível de complexidade das situações propostas, envolvendo a multiplicação, progride ano a ano. Para o 2응 ano do EF estão previstas as situações do Campo Conceitual Multiplicativo envolvendo 
a multiplicação aditiva e a comparação entre razões, explorando-se os significados da multiplicação com adição de parcelas iguais e proporcionalidade. No 30 ano, acrescentam-se situações do Campo Conceitual Multiplicativo envolvendo a configuração retangular. $E$ no $4 \stackrel{0}{0}$ ano do $E F$, além das situações multiplicativas anteriores, explora-se o raciocínio combinatório.

Dessa forma, espera-se que, ao final do ciclo dos anos iniciais do EF, tenham sido abordadas as quatro situações multiplicativas do Campo Conceitual Multiplicativo e os quatro significados da multiplicação: adição de parcelas iguais, proporcionalidade, configuração retangular e combinação.

Logo, o professor tem um papel fundamental na construção da aprendizagem do estudante, sendo necessário realizar um planejamento de aulas com atividades problematizadoras e contextualizadas, para a progressiva exploração dos conceitos multiplicativos. Além disso, a expectativa é de “que o estudante desenvolva diferentes estratégias para a obtenção dos resultados, sobretudo por estimativa e cálculo mental, além de algoritmos e uso de calculadoras." (BRASIL, 2017b, p.270).

Para que o estudante construa as habilidades propostas, a BNCC foca na explanação dos objetos de conhecimento através de situações argumentativas e desafiadoras (BRASIL, 2017b). Os objetos de conhecimento e habilidades indicados pela BNCC no ensino da multiplicação nos anos iniciais do EF destacam o uso de problemas para o desenvolvimento de habilidades pelo estudante, por meio da utilização de diferentes estratégias em sua resolução. Segundo Vergnaud (1990, p.135), “um conceito não pode ser reduzido à sua definição se estamos interessados na sua aprendizagem e no seu ensino. É por meio de situações e de problemas que um conceito adquire sentido para o aluno". Assim, aponta-se que a resolução de problemas é importante para a aprendizagem da multiplicação pelo estudante.

A BNCC evidencia a construção do conhecimento pelo estudante, mediada por diferentes estratégias de ensino a serem utilizadas pelo professor em sala de aula. Ao introduzir um conteúdo, torna-se necessário instigar e cativar o estudante. Para tanto, a resolução de problemas e as atividades investigativas são estratégias importantes na introdução da multiplicação, pois as mesmas permitem o estabelecimento de relações com o cotidiano dos estudantes.

As formas de aprendizagem estão relacionadas à maneira como os estudantes constroem o conhecimento. Às vezes, os conceitos relacionados à operação de multiplicação não estão sendo bem construídos pelos estudantes, causando-lhes falta de entusiasmo para aprender, pois, não sabem realizar, sequer, cálculos simples de multiplicação. Campos (1987, p.51) acrescenta que:

O indivíduo que aprende pensa sobre o que faz, ao aprender; forma, pelo menos, uma noção da natureza geral e do significado deste processo: se é interessante ou enfadonho, se constitui uma forma adequada de socialização, ou um exercício físico sadio. Ao mesmo tempo, adquire alguns sentimentos referentes à atividade: passa a apreciá-la ou desprezá-la, a detestá-la ou valorizá-la, e a atividade adquire uma conotação positiva ou negativa, atraindo-o ou repelindo-o. 
Há a necessidade de se reverem as práticas pedagógicas, para conseguir tornar prazeroso aquilo que é um desprazer em razão da falta de compreensão e temor do desconhecido. A Matemática carrega um estigma de "ser o conteúdo mais difícil", o que pode estar relacionado à falta de estímulos. Nesse sentido, Nürnberg (2008, p.3334) aponta que:

O conhecimento matemático é concebido como algo que emerge e é extraído do mundo físico pelo homem e por meio dos sentidos. Por isso, no processo ensino-aprendizagem da matemática, uma condição é a manipulação e visualização de objetos ou as atividades práticas. Didaticamente, são valorizados os conhecimentos que o aluno adquire com pesquisa, atividades experimentais e a resolução de problemas.

Corroborando a ideia de reconstrução das práticas pedagógicas, a BNCC traz a proposta de se trabalhar mais com atividades investigativas, deixando os estudantes mais autônomos e confiantes na resolução de um problema, ou na produção de uma escrita e fluência na leitura, formando seres pensantes e questionadores e não, simplesmente, indivíduos sem sonhos ousados e capazes de mudar a maneira como pensam e agem. (BRASIL, 2017b).

Às vezes, o ensino da multiplicação se torna ineficaz diante de obstáculos enfrentados nas escolas, como a falta de recursos, infraestrutura e professores qualificados. Além disso, os métodos de ensino precisam deixar de ser uma simples repetição, uma aula sem objetivo. O desenvolvimento de habilidades na resolução de operações matemáticas deve levar o estudante a desafiar sua capacidade, instigando-o a pensar e desenvolver estratégias na resolução de problemas relacionados ao seu cotidiano. Dante (1994, p.13) complementa que "não basta saber fazer mecanicamente as operações de adição, subtração, multiplicação e divisão. É preciso saber como e quando usá-las convenientemente na resolução de situações-problema".

Para a ocorrência de uma aprendizagem significativa, a BNCC indica que a proposta pedagógica da escola deva promover momentos de planejamento coletivos, oportunizando aos professores "decidir sobre formas de organização interdisciplinar dos componentes curriculares e fortalecer a competência pedagógica das equipes escolares para adotar estratégias mais dinâmicas, interativas e colaborativas em relação à gestão do ensino e da aprendizagem." (BRASIL, 2017b, p.18).

Uma dificuldade encontrada pelos professores dos anos iniciais está na resistência em mudar as estratégias pedagógicas. O ensino da multiplicação, na maioria dos casos, se faz somente pela associação com a soma de parcelas iguais, limitando a aprendizagem do estudante. Precisam-se explorar os outros significados da multiplicação, relacionando esse estudo a objetos de convívio dos estudantes, fazendo-os utilizar diferentes estratégias e procedimentos para resolver as situações multiplicativas.

\section{A MULTIPLICAÇÃO EM SALA DE AULA}

Nürnberg (2008) afirma que ensinar Matemática significa interligar os conhecimentos matemáticos aos conhecimentos cotidianos dos estudantes. Nesse sentido, Freire (1980, p.52) coloca que: 
O que se pretende é a problematização do próprio conhecimento em sua indiscutível reação com a realidade concreta na qual se gera e sobre a qual incide, para melhor compreendê-la, explicá-la, transformá-la. Se $4 \times 4$ são $16[\ldots]$ não há de ser por isto que o educando deve simplesmente memorizar que são 16 . [...] 4x4, sem uma relação com a realidade no aprendizado, sobretudo de uma criança seria uma falsa abstração. Uma coisa é $4 \times 4$ na tabuada que deve ser memorizada, outra coisa é $4 \times 4$ traduzidos na experiência concreta: fazer quatro tijolos quatro vezes. Em lugar de memorização mecânica de $4 \times 4$ impõe-se descobrir sua relação com um fazer humano.

Embasado nisso, o professor pode diversificar sua prática a fim de oportunizar maneiras diferentes de relacionar a tabuada com o cotidiano dos estudantes. Nürnberg (2008, p.92) defende que "a tabuada não seja apenas uma ação isolada da atividade de ensino/aprendizagem ou pré-requisito para bom desempenho nos algoritmos, mas um conceito fortemente articulado com outros de um sistema conceitual". A autora Ana Cristina Souza Rangel (1998) criou uma série de apostilas de alfabetização, e nelas, quando fala do ensino da tabuada, procura relacionar as leis matemáticas com objetos reais, de fácil assimilação do estudante e, em algumas vezes, com o concreto. No Quadro 3, por exemplo, ilustram-se as cinco primeiras multiplicações por 4, associadas à quantidade de patas de um cachorro:

Quadro 3 - Tabuada de multiplicação por 4.

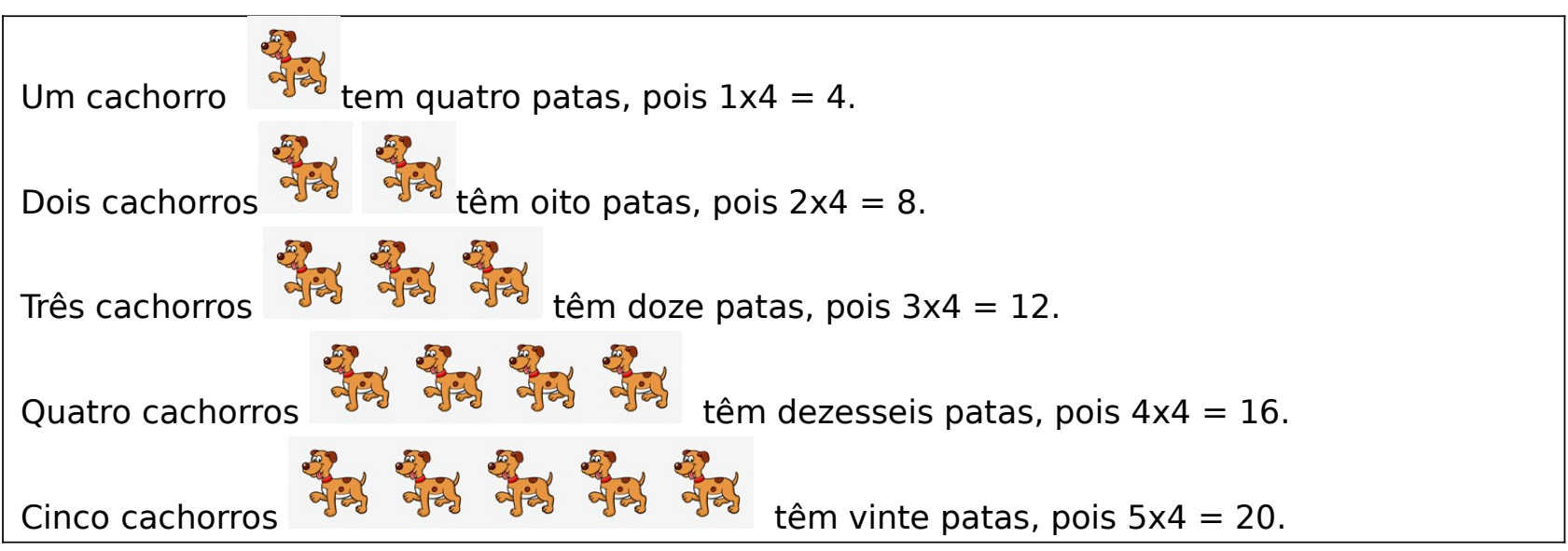

Fonte: Adaptado de Rangel (1998).

A lei da tabuada de multiplicação por 4 também pode ser relacionada com outros elementos, como o número de patas de um cavalo ou de um gato, e o número de rodas de um carro. No Quadro 4, apresentam-se possibilidades para associar as leis da tabuada de multiplicação com objetos reais/concretos e de fácil assimilação dos estudantes.

Dentre diversos recursos didáticos, Pires (2013) propõe o ensino das leis matemáticas por meio da construção da Tábua de Pitágoras, ilustrada na Figura 2, com a participação dos estudantes e orientados pelo professor. Essa é definida como uma "tabela de dupla entrada na qual são registrados os resultados da multiplicação dos números que ocupam a linha e a colunas principais" (PIRES, 2013, p. 148). Essa atividade permite ao estudante fazer comparações dos resultados da tabuada e, a partir disso, fazer deduções lógicas. 


\section{Revista Thema}

Quadro 4 - Possibilidades de associação das leis da tabuada de multiplicação.

\begin{tabular}{|l|l|}
\hline Leis da tabuada de multiplicação & Possibilidades \\
\hline Lei do 2 & Rodas de bicicleta e animais bípedes. \\
\hline Lei do 3 & Brinquedo giratório spinners. \\
\hline Lei do 4 & $\begin{array}{l}\text { Animais quadrúpedes, rodas de carro, número de pés } \\
\text { da cadeira e da mesa. }\end{array}$ \\
\hline Lei do 5 & Dedos da mão e do pé e estrela de cinco pontas. \\
\hline Lei do 6 & Patas da joaninha. \\
\hline Lei do 7 & $\begin{array}{l}\text { Dias da semana, as cores do arco-íris e notas } \\
\text { musicais. }\end{array}$ \\
\hline Lei do 8 & Patas da aranha. \\
\hline Lei do 9 & 9 quadradinhos das faces de um cubo mágico. \\
\hline Lei do 10 & Pinos do jogo de boliche. \\
\hline
\end{tabular}

Fonte: Adaptado de Rangel (1998).

Figura 2 - Tábua de Pitágoras.

\begin{tabular}{llllllllllll}
\hline $\mathbf{X}$ & $\mathbf{0}$ & $\mathbf{1}$ & $\mathbf{2}$ & $\mathbf{3}$ & $\mathbf{4}$ & $\mathbf{5}$ & $\mathbf{6}$ & $\mathbf{7}$ & $\mathbf{8}$ & $\mathbf{9}$ & $\mathbf{1 0}$ \\
\hline $\mathbf{0}$ & 0 & 0 & 0 & 0 & 0 & 0 & 0 & 0 & 0 & 0 & 0 \\
\hline $\mathbf{1}$ & 0 & 1 & 2 & 3 & 4 & 5 & 6 & 7 & 8 & 9 & 10 \\
\hline $\mathbf{2}$ & 0 & 2 & 4 & 6 & 8 & 10 & 12 & 14 & 16 & 18 & 20 \\
\hline $\mathbf{3}$ & 0 & 3 & 6 & 9 & 12 & 15 & 18 & 21 & 24 & 27 & 30 \\
\hline $\mathbf{4}$ & 0 & 4 & 8 & 12 & 16 & 20 & 24 & 28 & 32 & 36 & 40 \\
\hline $\mathbf{5}$ & 0 & 5 & 10 & 15 & 20 & 25 & 30 & 35 & 40 & 45 & 50 \\
\hline $\mathbf{6}$ & 0 & 6 & 12 & 18 & 24 & 30 & 36 & 42 & 48 & 54 & 60 \\
\hline $\mathbf{7}$ & 0 & 7 & 14 & 21 & 28 & 35 & 42 & 49 & 56 & 63 & 70 \\
\hline $\mathbf{8}$ & 0 & 8 & 16 & 24 & 32 & 40 & 48 & 56 & 64 & 72 & 80 \\
\hline $\mathbf{9}$ & 0 & 9 & 18 & 27 & 36 & 45 & 54 & 63 & 72 & 81 & 90 \\
\hline $\mathbf{1 0}$ & 0 & 10 & 20 & 30 & 40 & 50 & 60 & 70 & 80 & 90 & 100 \\
\hline & & & & 50 & 0 &
\end{tabular}

Fonte: Adaptado de Pires (2013).

Dessa forma, o uso de materiais manipuláveis para ensinar a multiplicação permite ao estudante construir sua aprendizagem, durante o seu manuseio ou fazendo a relação das leis matemáticas a objetos reais, aprofundando e ampliando seus significados. É importante que o professor planeje suas aulas de modo a utilizar diferentes recursos didáticos, para mediar e auxiliar a construção de habilidades relacionadas ao objeto de conhecimento multiplicação.

Por conseguinte, é essencial que o professor elabore atividades argumentativas e mentais para a construção da aprendizagem do estudante. No ensino da multiplicação o professor deveria propor atividades com materiais concretos, tais como: palitos de picolé, canudinhos, tampinhas de garrafas, dados, ábaco, material dourado e outros, 
de acordo com a criatividade do professor e relacionados ao cotidiano do estudante para construção da aprendizagem significativa, partindo, gradativamente, da ideia de soma de parcelas iguais para configuração retangular, proporcionalidade e combinação.

Em conformidade ao uso de diferentes formas de ensino para a construção do conhecimento do estudante, Colinvaux (2007, p.32) afirma que "aprender deverá ser entendido como um processo que envolve a produção, criação e uso de significações, associando a aprendizagem dos estudantes a processos de compreensão do mundo material e simbólico, gerando a mobilização de significados, criando e recriando-os". Nesse sentido, o uso de atividades lúdicas no ensino de multiplicação também favorece a aprendizagem de situações multiplicativas. O professor poderia propor atividades de ensino diferenciadas e fazer o uso do lúdico, definido por Maluf (2008, p.42) como:

As atividades lúdicas são instrumentos pedagógicos altamente importantes, mais do que apenas divertimento, são um auxílio indispensável para o processo de ensino aprendizagem, que propicia a obtenção de informações em perspectivas e dimensões que perpassam o desenvolvimento do educando. A ludicidade é uma tática insubstituível para ser empregada como estímulo no aprimoramento do conhecimento e no progresso das diferentes aprendizagens.

O ensino de Matemática com o uso do jogo, desperta no estudante o desenvolvimento intelectual e emocional, amenizando a complexidade dos conteúdos e o desencadeamento de bloqueios, principalmente, em estudantes com dificuldades de aprendizagem.

O lúdico apresenta dois elementos que o caracterizam: o prazer e o esforço espontâneo. Ele é considerado prazeroso, devido a sua capacidade de absorver o indivíduo de forma intensa e total, criando um clima de entusiasmo. [...] Em virtude desta atmosfera de prazer dentro da qual se desenrola, a ludicidade é portadora de um interesse intrínseco, canalizando as energias no sentido de um esforço total para consecução de seu objetivo. Portanto, as atividades lúdicas são excitantes, mas também requerem um esforço voluntário. [...] As situações lúdicas mobilizam esquemas mentais. Sendo uma atividade física e mental, a ludicidade aciona e ativa as funções psico-neurológicas e as operações mentais, estimulando o pensamento. [...] O ser que brinca e joga é, também, o ser que age, sente, pensa, aprende e se desenvolve. (TEIXEIRA, 1995, p.23).

Nesse contexto, o professor deveria deixar claro o objetivo de aprendizagem de um jogo, estimulando a construção de novos conhecimentos pelos estudantes. Acrescenta-se que:

O uso de jogos, nas aulas de matemática, deve ser orientado pelo professor na busca de uma intervenção pedagógica construtiva. Para jogar com competência os estudantes devem ter conhecimento das regras do jogo e suas instruções, pois o estudante "[...] ao jogar e refletir sobre suas jogadas e jogadas possíveis, adquire certa 'competência' naquele jogo, ou seja, o jogo passa a ser considerado sob vários 
aspectos e óticas que inicialmente poderiam não estar sendo considerados." (GRANDO, 2000, p.45, grifo do autor).

Assim, o uso de jogos na sala de aula, precisa ser um instrumento de aprendizagem com objetivos, sendo necessário um conhecimento prévio do professor sobre o jogo para que este faça sentido em suas aulas e auxilie nas resoluções de operações e problemas matemáticos, pois, de acordo com Grando (2000, p.43):

[...] o processo de sistematização dos conceitos e/ou habilidades do pensamento matemático que vão emergindo no decorrer das situações de jogo deve ser desencadeado pelo profissional responsável pela intervenção pedagógica com os jogos, seja o professor, o pesquisador ou o psicopedagogo. É durante esse processo que são garantidas algumas estruturas matemáticas, desejadas numa situação de intervenção com jogos para o ensino da Matemática. A sistematização possibilita evidenciar para o sujeito o conceito que ele está trabalhando, as relações que está percebendo, as regularidades que podem ser observadas, a constatação de suas hipóteses e a possível aplicação de tais ideias a outras situações.

Diante de tais reflexões, percebe-se que é fundamental a participação do professor no processo de mediação da prática do jogo, para que os estudantes desenvolvam habilidades matemáticas, podendo aproveitar os conhecimentos construídos ao jogar na resolução de novas situações. Ao utilizar jogos como um recurso didático, o professor precisa saber o que se pretende ao jogar, ou seja, qual o seu enfoque.

Para abordar a multiplicação, defende-se que o professor deve fazer uso de diferentes tipos de jogos, como por exemplo: velha da multiplicação; bingo das leis da multiplicação; trilha da multiplicação; entre outros que podem ser encontrados em livros, na internet, ou elaborados pelos próprios estudantes em conjunto com o professor, observando-se os objetivos de aprendizagem. Nesse contexto, Grassi (2008, p.103) afirma que:

A utilização dos jogos e brincadeiras na educação, no trabalho pedagógico e psicopedagógico, com sujeitos que apresentem ou não dificuldades de aprendizagem, apresenta-se como uma alternativa interessante, pois pode despertar o interesse e o desejo de aprender e, ao mesmo tempo, pode possibilitar o desenvolvimento de estrutura de pensamento mais elaboradas, a apropriação e a construção de conhecimento, enfim a aprendizagem.

O estudante precisa ser estimulado a desenvolver as habilidades necessárias para construção do conhecimento e, posteriormente, utilizá-los em diversos contextos propostos a ele. Para isso, o professor precisa aceitar que o uso dos jogos deveria ser direcionado, observado e mediado para atingir os objetivos propostos no planejamento das aulas. Assim, Grassi (2008) defende que durante os jogos o professor deveria:

Observar atentamente as situações de jogo para levantar informações sobre o estilo de jogo e as características de cada participante, como jogam e como tiram proveito de regras e situações que acontecem ao longo das partidas. Deve promover conversações e análises com os participantes sobre suas ações e estratégias, dúvidas, dificuldades, 
modificações nas estratégias e nas regras, criação de alternativas para jogar o jogo e sobre o resultado das partidas. Pode propor regras novas ou desafios que tornem os jogos mais interessantes ou mais difíceis. (GRASSI, 2008, p.12).

A inclusão de jogos nas aulas de Matemática para ensinar a multiplicação é desafiadora, requer planejamento e conhecimento do professor sobre as regras, pois, de acordo com Grassi (2008), o professor precisa acompanhar todo o processo de modo a favorecer que os estudantes consigam participar da atividade e construir conhecimento. Ao jogar, o estudante consegue resolver situações problema de forma cooperativa com o seu colega, sanando dúvidas e construindo aprendizagens de maneira natural, pois, a cada jogada, avalia as possibilidades de ganhar e planeja sua ação, buscando estratégias eficientes na intenção de obter melhores resultados.

Destaca-se ainda a aplicabilidade dos recursos tecnológicos como aparato pedagógico no ensino da multiplicação, pois a utilização de internet, softwares, calculadora, jogos educativos e a realidade virtual trazem mais possibilidades de aprendizagem. Segundo Silva, Cortez e Oliveira (2013, p.88) "o uso de computadores e softwares educativos já faz parte do cotidiano de muitos estudantes, tanto para elaboração de trabalhos escolares ou como entretenimento". Nesse contexto, os recursos tecnológicos tornam o processo de ensino mais dinâmico, o que corrobora com Mueller $(2013$, p.36):

$\mathrm{Na}$ perspectiva educacional, a utilização das tecnologias como ferramenta didática possibilita uma prática educacional desafiadora tanto para o aluno quanto para o professor, pois trabalha com uma proposta pedagógica mais ampla, responsável pela motivação e interação. O educador e a escola precisam estar preparados para essa mudança e oferecer ao educando o que a sociedade exige. Torná-los indivíduos integrados neste contexto tecnológico é também papel do docente, é um dever que não podemos abandonar, pois estes adolescentes e jovens estarão em curto espaço de tempo inseridos no mercado de trabalho. Suas oportunidades aumentarão ou diminuirão de acordo com o preparo e o que a escola os oferece. Não podemos esquecer que para muitos desses alunos a escola é, talvez, o único local ao seu alcance capaz de oferecer conhecimento, alimentação, alegria, lazer, esportes, talentos e cultura.

Nesse caso, o professor precisa acreditar na necessidade de inovações na educação e se preparar para tal, por meio de cursos de capacitação e especializações que contribuam para a exploração desses recursos em sala de aula. Para Ribeiro e Paz (2012), os envolvidos na educação, professores, estudantes e funcionários, precisam encarar as inovações tecnológicas de forma a contribuir no espaço escolar e não com olhos de reprovação, pois as mudanças devem ser aceitas com otimismo e introduzidas no ambiente escolar a fim de promover a verdadeira educação a serviço do bem comum, na busca de construir um futuro melhor, uma sociedade mais humana e igualitária.

Com o propósito de promover o ensino de maneira atrativa, nota-se o aumento no desenvolvimento de softwares (programas) educacionais. De acordo com Bittar (2010, p.221) um software "é chamado de educacional quando é desenvolvido com objetivos 
claramente pedagógicos". Dentro desse contexto, existem diversos programas gratuitos e de fácil acesso, de modo a favorecer a participação ativa dos estudantes na construção de sua aprendizagem.

Nesse universo tecnológico se encontra uma diversidade de softwares para o ensino da multiplicação. Bona $(2009$, p.2) ressalta que um software será relevante para o ensino da Matemática se "o seu desenvolvimento estiver fundamentado em uma teoria de aprendizagem cientificamente comprovada para que ele possa permitir ao aluno desenvolver a capacidade de construir, de forma autônoma, o conhecimento sobre um determinado assunto".

O uso dos recursos tecnológicos ainda não faz parte de boa parte das escolas públicas brasileiras, de acordo com a pesquisa Tecnologias da Informação e Comunicação na Educação (TIC Educação) ${ }^{4}$, realizada em 2016, pelo Centro Regional de Estudos para o Desenvolvimento da Sociedade da Informação (Cetic.br). Os dados indicam que: $81 \%$ das escolas públicas do Brasil têm laboratório de informática, mas somente $59 \%$ são utilizados, devido a problemas de baixa conexão e equipamentos ultrapassados, que inviabilizam o uso da internet e de computadores. Diante desse cenário, é possível observar que o uso desses recursos tecnológicos no ambiente escolar é limitado.

Apesar disso, cabe ao professor inovar e utilizar diversos recursos tecnológicos, além dos computadores, como a calculadora, que atrai a atenção dos estudantes quando utilizada para fins educacionais. De acordo com os Parâmetros Curriculares Nacionais (PCN):

Estudos e experiências evidenciam que a calculadora é um instrumento que pode contribuir para a melhoria do ensino da Matemática. A justificativa para essa visão é o fato de que ela pode ser usada como um instrumento motivador na realização de tarefas exploratórias e de investigação. Além disso, ela abre novas possibilidades educativas, como a de levar o aluno a perceber a importância do uso dos meios tecnológicos disponíveis na sociedade contemporânea. A calculadora é também um recurso para verificação de resultados, correção de erros, podendo ser um valioso instrumento de autoavaliação. (BRASIL, 1997, p.34).

Dentre os recursos tecnológicos que podem ser utilizados no ensino da multiplicação, também se encontra o software Tabuada do Dino ${ }^{5}$, podendo ser usado para o estudo das quatro operações ou para cada uma delas de forma individualizada. A Tabuada do Dino é um recurso para fazer cálculos mentais e de forma individual, estando de acordo com estudos realizados por Almeida e Almeida (2015, p.10), pois a utilização dos softwares educacionais na aprendizagem do estudante "deve estar inserida em um contexto e em uma situação de ensino baseados em uma metodologia que oriente o processo, através da interação, da motivação e da descoberta, facilitando a aprendizagem de um conteúdo".

Segundo a BNCC, uma das competências específicas para o ensino de Matemática no EF é a de o estudante ser capaz de "utilizar processos e ferramentas matemáticas,

\footnotetext{
${ }^{4}$ A pesquisa TIC Educação busca mapear, desde 2010, o uso e o acesso das ferramentas tecnológicas em escolas. O levantamento é feito com alunos, professores e coordenadores pedagógicos.

${ }^{5}$ Disponível em: <http://www.escolagames.com.br/jogos/tabuadaDino>. Acesso em: 8 nov. 2019.
} 
inclusive tecnologias digitais disponíveis, para modelar e resolver problemas cotidianos, sociais e de outras áreas de conhecimento, validando estratégias e resultados." (BRASIL, 2017b, p.269). Sendo assim, é possível complementar que a utilização das tecnologias educacionais é válida para a construção da aprendizagem do estudante, pois permite ao mesmo ter um suporte pedagógico significativo para atividades a serem realizadas na escola e/ou fora dela. Nesse sentido, é importante a mediação do professor para motivar o estudante na busca de softwares educacionais, vídeos e outros recursos tecnológicos, como auxílio na resolução de problemas e atividades investigativas.

\section{CONSIDERAÇÕES FINAIS}

Neste artigo, a partir da TAS, do Campo Conceitual Multiplicativo de Vergnaud e do documento da BNCC, foram discutidos conceitos multiplicativos e propostos processos matemáticos e atividades para o ensino da multiplicação nos anos iniciais do EF.

A área de Matemática na BNCC apresenta a operação de multiplicação na unidade temática números, a partir do 2 o ano, e é desenvolvida de forma gradativa, por meio de objetos de conhecimento e habilidades, explorando-se as ideias de adição de parcelas iguais, proporcionalidade, disposição retangular e combinação. Considerando esses conceitos multiplicativos, acredita-se que a resolução de problemas e de atividades investigativas, deveria acontecer com o uso de materiais concretos e manipuláveis, como: palitos de picolé, ábaco, material dourado, tabela de Pitágoras e outros; permitindo encontrar soluções, utilizando-se conhecimentos relevantes já adquiridos. Acrescenta-se a importância de associar o estudo das leis da tabuada de multiplicação a elementos do cotidiano dos estudantes, para que possam compreendê-la e não apenas memorizá-la.

Com o objetivo de introduzir novas aprendizagens e de fixar as preexistentes, o uso de jogos pedagógicos contribui positivamente na resolução de situações multiplicativas, pois possibilita ao estudante racionar, esquematizar e elaborar estratégias de resolução. Os recursos tecnológicos, como a calculadora, o computador e os softwares educacionais, propiciam ao estudante adquirir habilidades para modelar e resolver problemas cotidianos, validando estratégias e resultados, contribuindo para uma aprendizagem significativa.

Por fim, o professor tem papel de mediador no processo de ensino e precisa planejar situações de aprendizagem que envolvam os estudantes de forma ativa na construção dos conceitos relacionados à operação de multiplicação, considerando as orientações presentes na BNCC e a realidade escolar.

\section{REFERÊNCIAS}

ALMEIDA, Rosa Lívia Freitas de; ALMEIDA, Carlos Alberto Santos de. Fundamentos e análise de software educativo. 2. ed. Fortaleza, CE: UECE, 2015. 
BITTAR, Marilena. A escolha do software educacional e a proposta Didática do professor: estudo de alguns exemplos em matemática. In: ROCHA, Carlos Alves et al. Educação Matemática, tecnologia e formação de professores: algumas reflexões. Campo Mourão: Editora da FECILCAM, 2010. p.215-242.

BONA, Berenice de Oliveira. Análise de softwares educativos para o ensino de Matemática nos anos iniciais do ensino fundamental. Experiências em Ensino de Ciências, Carazinho, v.4, p.35-55, mai. 2009.

BRASIL. Ministério da Educação. INEP - Instituto Nacional de Estudos e Pesquisas Educacionais Anísio Teixeira. Resultados do Saeb 2017. 2017a. Disponível em: <http://portal.inep.gov.br/web/guest/educacao-basica/saeb>. Acesso em: 7 set. 2019.

BRASIL. Ministério da Educação. Secretaria de Educação Básica. Base Nacional Comum Curricular. Brasília: MEC/SEB, 2017b. Disponível em: < http://basenacional comum.mec.gov.br/images/BNCC_20dez_sitepdf>. Acesso em: 9 set. 2019.

BRASIL. Ministério da Educação. Secretaria de Educação Fundamental. Parâmetros Curriculares Nacionais: Matemática. Brasília: MEC/SEF, 1997.

CAMPOS, Dinah Martins de Souza. Psicologia da aprendizagem. 11. ed. Petrópolis: Vozes, 1987.

COLINVAUX, Dominique. Aprendizagem e construção/constituição de conhecimento: reflexões teórico-metodológicas. Pró-Posições, Campinas, v.18, n.3, p.29-51, set./dez. 2007.

DANTE, Luis Roberto. Didática da matemática na pré-escola. São Paulo: Ática, 1994.

FREIRE, Paulo. Extensão e comunicação? Rio de Janeiro: Paz e Terra, 1980.

GIL, Antônio Carlos. Como elaborar projetos de pesquisa. 6. ed. São Paulo: Atlas, 2017.

GRANDO, Regina Célia. O conhecimento matemático e o uso de jogos na sala de aula. 2000. 224 f. Tese (Doutorado em Educação) - Universidade Estadual de Campinas, Campinas, 2000.

GRASSI, Tania Mara. Oficinas psicopedagógicas. 2. ed. Curitiba: Ibpex, 2008.

MALUF, Ângela Cristina Munhoz. Atividades lúdicas para Educação Infantil: conceitos, orientações e práticas. Rio de Janeiro: Vozes, 2008.

MOREIRA, Marco Antonio. Aprendizagem significativa: a teoria e texto complementares. São Paulo: Livraria da Física, 2012.

MUELLER, Liliane Carine. Uso de recursos computacionais nas aulas de Matemática. 2013. 117 f. Dissertação (Mestrado em Ensino de Ciências Exatas) Universidade do Vale do Taquari, Lajeado, 2013.

NOVAK, Joseph D.; CAÑAS, Alberto J. A teoria subjacente aos mapas conceituais e como elaborá-los e usá-los. Práxis Educativa, Ponta Grossa, v.5, n.1, p.9-29, 2010. 
NÜRNBERG, Joyce. Tabuada: significados e sentidos produzidos pelos professores das séries iniciais do Ensino Fundamental. 2008. 95 f. Dissertação (Mestrado em Educação) - Universidade do Extremo Sul Catarinense, Criciúma, 2008.

PINTO, Neuza Bertoni. O erro como estratégia didática: estudo do erro no ensino da matemática elementar. Campinas: Papirus, 2000.

PIRES, Célia Maria Carolino. Números naturais e operações. São Paulo: Melhoramentos, 2013.

PRODANOV, Cleber Cristiano; FREITAS, Ernani Cesar de. Metodologia do trabalho científico: métodos e técnicas da pesquisa e do trabalho acadêmico. 2. ed. Novo Hamburgo: FEEVALE, 2013.

RANGEL, Ana Cristina Souza. Matemática da minha vida: 3a série. Porto Alegre: Naila Freitas, 1998.

RIBEIRO, Flávia Martins; PAZ, Maria Goretti. O ensino da matemática por meio de novas tecnologias. Revista Modelos - FACOS/CNEC Osório, Osório, v.2, n.2, p.1221, ago. 2012.

SANTOS, Aparecido dos. Formação de professores e as estruturas multiplicativas: reflexões teóricas e práticas. Curitiba: Appris, 2015.

SILVA, Marcílio Farias de; CORTEZ, Rita de Cássia Costa; OLIVERIA, Viviane Barbosa de. Software educativo como auxílio na aprendizagem da matemática: uma experiência utilizando as quatro operações com alunos do 4 o ano do Ensino Fundamental I.

Revista ECCOM - Educação, Cultura e Comunicação, Lorena, v.4, n.7, jan./jun. 2013.

TEIXEIRA, Carlos E. J. A ludicidade na escola. São Paulo: Loyola, 1995.

VERGNAUD, Gerard. A criança, a matemática e a realidade. Tradução de Maria Lucia Faria Moro. Curitiba: UFPR, 2009.

VERGNAUD, Gerard. A Teoria dos Campos Conceituais. In: BRUN, J. Didáctica das Matemáticas. Lisboa: Instituto Piaget, 1996.

VERGNAUD, Gerard. La théorie des champs conceptuels. Récherches en Didactique des Mathématiques, Grenoble, França, v.10, n.23, p.133-170, 1990.

VERGNAUD, Gerard. The Classification of Cognitive Tasks and Operations of Thought Involved in Addition and Subtraction Problems. In: CARPENTER, T.; ROMBERG, T.; MOSER, J. (Orgs.). Addition and Subtraction: a cognitive Perspective. New Jerssey: Lawrense Erlbaun, 1982. p.39-59.

Submetido em: 08/02/2020

Aceito em: 13/04/2020 